\title{
El amor en los tiempos de las Princesas de Disney
}

\author{
Lorena Beloso* y Marisol Fullana** \\ Universidad Católica de las Misiones, Argentina \\ Grupo en Formación Catamarca IOM2, Argentina
}

Recibido: 23 de septiembre 2019; aceptado: 22 de octubre 2019

\begin{abstract}
Resumen
El "maravilloso Mundo de Disney", a partir de sus Princesas, propone estereotipos femeninos como posibles respuestas a la pregunta freudiana sobre que quiere una mujer. Desde la primera aparición hasta la actualidad, estas princesas fueron modificando sus posiciones y semblantes, según el discurso del amo imperante. De igual manera se vio transformada su relación a los hombres, y el lugar que otorgan al amor. Desde la década del 30 , con el modelo de madre y ama de casa, pasando por los 60 con la liberación sexual, y los primeros movimientos feministas, a la actualidad donde los feminismos toman protagonismo, las mujeres fueron reinventándose, y con ella sus lazos, al otro, y en consecuencia al Otro.
\end{abstract}

Palabras clave: Disney Princesas | amor | goce| feminismos | síntoma social

Love in the time of Disney princesses

\begin{abstract}
The "Wonderful Disney World", from its Princesses, proposes female stereotypes as possible answers to the Freudian question about what a woman wants. From the first appearance to the present, these princesses were modifying their positions and countenance, according to the discourse of the prevailing master. In the same way their relationship to men was transformed, and the place they give to love. Since the 30 s, with the model of mother and housewife, going through the $60 \mathrm{~s}$ with sexual liberation, and the first feminist movements, to the present where feminisms take center stage, women were reinventing themselves, and with it their ties, to the other, and consequently to the Other.
\end{abstract}

Keywords: Disney Princesses |love | jouissance | feminisms | social symptom

Si decimos que Disney es una de las compañías de entretenimiento y comunicación más influyente de la cultura contemporánea, es porque además de tener entre sus personajes al ratón más famoso del mundo, ha sabido forjar un imperio que se fue expandiendo de manera monumental desde sus inicios. Una de sus franquicias más importantes es la que conocemos como Disney Princess, siendo catorce personajes los que lo integran hasta el momento: Blancanieves (primer largometraje de la compañía), Cenicienta, Aurora, Ariel, Bella, Jazmín, Pocahontas, Mulan, Tiana, Rapunzel, Mérida, Anna, Elsa, Moana. Todos ellos protagonistas femeninos, algunos tomados de la literatura, otros son adaptaciones de la historia universal y también hay creaciones originales de la cadena.

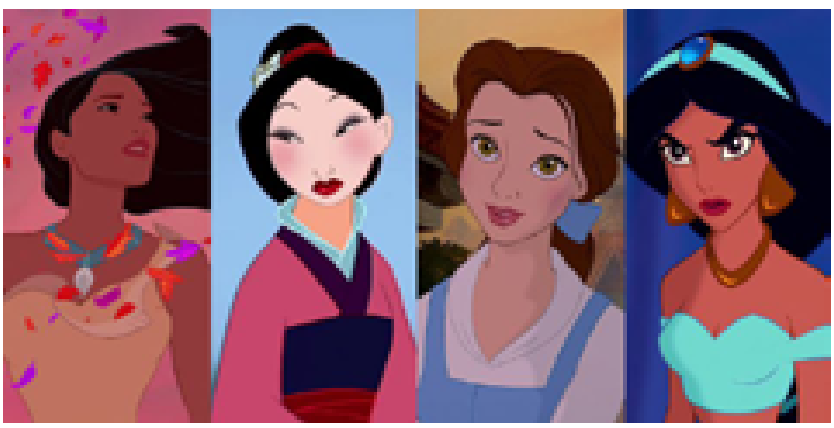

Podríamos pensar que, en sus orígenes, el "Maravilloso Mundo de Disney” proponía un estereotipo femenino, elaborando respuestas a la pregunta freudiana sobre qué quiere una mujer (Freud, 1925). Así, desde fines de los años 30 y hasta los 60 , fue la princesa que desea ser 
rescatada por un príncipe, a partir de un beso de amor, la versión más repetida y tradicionalmente conocida. Blancanieves (Disney, 1973), Cenicienta (Disney, 1950) y La Bella Durmiente, Aurora, (Disney, 1959) son damitas que se dedican al cuidado maternal (con enanos o animales) y tareas domésticas, invirtiendo mucho de su tiempo en ensoñaciones diurnas y fantasías que involucran un príncipe, lo que les permite a su vez escapar de su cruda realidad, generada por su némesis femenino: una bruja malvada, una madrastra desalmada y un hada oscura y resentida.

Es posible ubicar por ejemplo, que Blancanieves inicia entonando deseo que un gentil galán me entregue su amor, un día encantador mi príncipe vendrá y dichosa en sus brazos iré a un castillo bechizado de amor... Un día volverá rendido de pasión y por fin mi sueño se realizará, lo siento aqui en mi corazón. En la misma línea, Cenicienta, se presenta diciendo si amor es el bien deseado en dulces sueños llegará y en el baile, cuando finalmente conoce al príncipe, canta esto es amor, es todo cuanto soñé... mi corazón puede volar, estrellas ya puedo tocar. Esto es el milagro aquél que tanto yo soñé, esto es amor. Aurora asi también expresa quisiera con mi melodía encontrar algún día al hombre que espero y al fin se enamore de mi; $y$ en el bosque cuando aparece el príncipe cantando refiere eres tú el príncipe azul que yo soñé...eres tú la dulce ilusión que yo soñé. Aquellos clásicos proponen modelos femeninos a la espera de un gran amor que modifique su situación actual.

En la década del 90 nuevas princesas hacen su aparición: en La Bella y la Bestia (Trousdale y Wise, 1991), Bella una mujer que ama leer, desestima la propuesta de casamiento del soltero más codiciado del pueblo y no teme enfrentarse a una bestia para rescatar a su padre, y Mulan (Bancroft y Cook, 1998) una valiente guerrera oriental que ocupa el lugar de su progenitor en batalla para protegerlo. Pocahontas (Gabriel y Goldberg, 1995), una nativa americana con tatuajes que dispone de su cuerpo a su gusto. Jóvenes decididas que encuentran, esta vez sin añorarlo, el amor de hombres protectores y cariñosos que se dejan asombrar por estos nuevos semblantes femeninos, que promueven mujeres capaces de enfrentar la adversidad por ellas mismas. Bella, por ejemplo termina convirtiendo con su amor a aquella bestia maldita en un príncipe encantado, y Pocahontas le muestra, en la versión animada, a John Smith - un egocéntrico explorador - el valor de la naturaleza que los rodea y así se enamoran.

Las últimas producciones de la cadena, presentan en cambio princesas en una búsqueda diferente, Anna y Elsa, las hermanas de Frozen (Buck y Lee, 2013), nos muestran que el acto de amor necesario para la salvación no proviene de un hombre. Y Moana (Clements y Musker, 2016), la hija del jefe de una tribu, movilizada por el amor hacia su tierra, protege a su aldea aventurándose a una peligrosa odisea. Pareciera que aquí, ya no es la pregunta freudiana sobre qué desea una mujer la que orienta el argumento, sino más bien "qué puede una mujer". Las figuras masculinas cambian rotundamente: lejos del estereotipo del príncipe azul, en la primera serán un noble de linaje incierto que sólo busca aprovecharse del título nobiliario de las hermanas, y un trabajador un tanto torpe pero valiente; en la segunda un semidiós narcisista y egoísta que finalmente cede en ayudar a la joven líder, entablando una honesta amistad con ella.

Nos preguntamos entonces, ¿qué cambia y qué permanece en el recurso al tópico del amor en esta serie de películas?

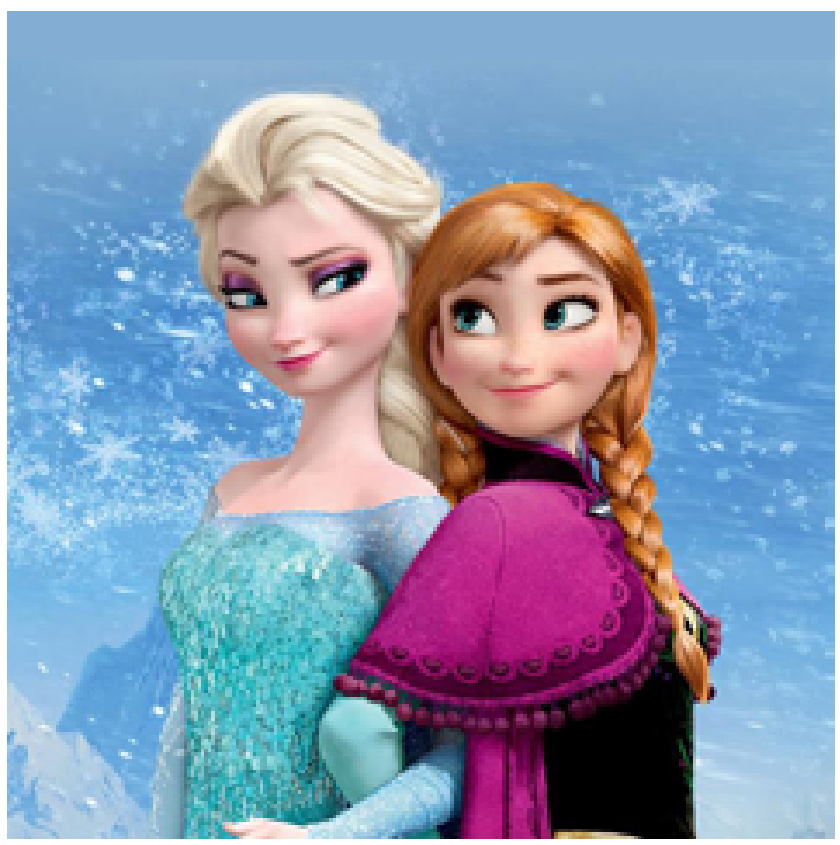

\section{Los primeros movimientos feministas y sus efectos}

El recorrido por la historia universal, y por la saga de las Princesas, nos permite constatar que las mujeres han ido mutando a lo largo del tiempo y transformándose en su esfera privada, y a partir de allí incidiendo en lo social y político. Puede pensarse en el papel cultural desarrollado por las mujeres antes de la década del 60, mujeres que se dedicaban al cuidado de sus hijos y esposos en po- 
sición maternal, como el tiempo de aquellas inaugurales princesas de Disney.

En los años 60, surgen los primeros movimientos feministas del siglo XX, lograr la igualdad de derechos y responsabilidades entre hombres y mujeres era uno de sus objetivos principales (Mallet, 2010). Los 60 - 70 inauguran un nuevo momento social, bajo el slogan "lo personal es político" las mujeres se congregan, proponiendo nuevos ideales respecto de lo que define a la mujer. Logran desplazar problemas pertenecientes a la intimidad y lo cotidiano, a problemas de sociedad buscando incidir en la política. Cuestionando de este modo, el punto de vista masculino que ubicó el poder. Se buscaba luchar contra las relaciones jerárquicas entre los sexos dejando en claro que estas no responden a las diferencias biológicas, sino a relaciones de poder.

Entonces, lo femenino ya no se reduce al ser madre. Nuevas reivindicaciones movilizan a las mujeres, de las cuales dos son principales: el derecho al propio cuerpo (con el aborto legal, seguro y gratuito), y contra la violencia sexual y los femicidios. A partir del empoderamiento, entendiendo a este por adquisición de poder e independencia por parte de un grupo social desfavorecido para mejorar su situación, las mujeres emergen como sujetos políticos, en lucha contra la opresión y la violencia.

Con este movimiento, se comienza a reconfigurar la identificación de la mujer con el ideal romántico sentimental. En este momento de la historia, "la religión femenina del amor dejó de darse por sentada" (Lipovetsky, 1999, p. 22), y las mujeres comenzaron a rehusarse a abandonar estudios o su profesión en nombre del ideal amoroso. Sin embargo, remarca Lipovetsky (1999) "no hay que hacerse ilusiones: incluso en lo más álgido del periodo contestatario, las mujeres jamás han renunciado a soñar con el amor” (p. 23).

Quizá esta propuesta nos permita abordar a las “princesas de los 90" (Bella, Mulan, y Pocahontas) quienes se dejan sorprender por el amor, más allá de que su ideal de vida estaba atravesado por la posibilidad de la elección propia, del derecho a decir no a lo impuesto por la familia, la tradición o los ideales sociales y las costumbres culturales. Cuando un hombre, aunque ya no con atributos del príncipe clásico aparece, consienten al amor. Esta perspectiva dialoga también con lo expuesto por Miller (1998) "es claro; la mujer moderna tiende a hacer del hombre un pequeño a, ella le dice "eres a penas un medio de goce" y eso va junto con una desvalorización del amor, pero no es verdad, es puro teatro" (p. 83).

\section{Las princesas de la época actual y el amor}

En la nueva era de las Princesas de Disney, una fórmula se repite: ya no será la espera del prince charming lo central de la historia. Incluso, como espectadores, no aguardamos más que aparezca para que el desenlace acontezca, y como propone Assef (2013) pensar sobre cómo miramos permite reflexionar sobre cómo vivimos. Las princesas actuales se presentan con una nueva mascarada de lo femenino, una nueva forma de velar el sintagma lacaniano "no hay relación sexual" (Lacan, 197172, p. 13).

Si la década del 70, con la liberación sexual que promovía favoreció el encuentro entre hombres y mujeres, bajo el lema "hagamos el amor y no la guerra", cabe preguntarse qué lugar hay en la actualidad para el encuentro amoroso entre los sexos, y de qué manera los feminismos repercuten en ello. En este sentido, M-H Brousse (s/f) plantea que el feminismo actual ya no se organiza por la reivindicación respecto a lo masculino, sino por la paridad, lo que decanta en que cada sexo va de su lado sin interesarse en el otro, y por ende en el Otro.

¿Podemos pensar entonces, al rechazo del amor como síntoma contemporáneo? Lo que las "princesas" nos muestran a nuestro parecer, es que hay un cambio de discurso en relación al amor, una localización diferente del goce y el amor en la sociedad contemporánea, lo cual daría lugar a otros vínculos posibles.

Síntoma social, en tanto entraña un nuevo arreglo del sujeto con la división, un nuevo modo de hacer con la división entre el amor y la pulsión: el rechazo del amor tal como está planteado al homologar las posiciones masculina y femenina. Una nueva oferta para las mujeres en nombre del feminismo en vía de obtener la igualdad en términos de derechos, impulsando a borrar las diferencias. Lo que era específico de lo femenino, ese saber hacer con el amor, se pierde: puede situarse del lado del goce, sin recurrir al amor.

En esta misma línea, J-A Miller (2012) propone:

(...) el crecimiento del "Uno" se traduce en el plan político por la democracia a diestra y siniestra: el derecho de cada uno a su propio goce se convierte en un "derecho humano”. ¿En nombre de qué mi goce sería menos ciudadano que el tuyo? Ya no es comprensible. (p. 7)

Es esta la apuesta de la cultura actual gobernada por la reivindicación de la prescindencia de los temas del amor y el empuje al goce.

En sentido inverso, el psicoanálisis propone conducir al sujeto a un nuevo amor, no a eliminarlo: que las 
mujeres puedan consentir a un amor que no implique desaparecer en el encuentro con el otro.

Así, lo amoroso sigue siendo una vía privilegiada para reintroducir las diferencias. Dando lugar a que la vida amorosa se presente bajo semblantes diferentes, alojando el desamparo esencial del sujeto, funcionando como suplencia al vacio que existe en la relación entre los sexos.

\section{Referencias}

Assef, J. (2013). La subjetividad Hipermoderna. Una lectura de la época desde el cine, la semiótica y el psicoanálisis. Buenos Aires: Gramma.

Brousse, M-H (s/f). El nuevo feminismo, lacaniano. Textos de la Nueva Escuela Lacaniana de la Ciudad de México. Recuperado de http://www.nel-mexico.org/articulos/seccion/textosonline/subseccion/Goce-femenino/742/El-nuevo-feminismo-lacaniano-1\#.

Coats, P (productor). Bancroft T., Cook, B (directores). (1998). Mulan [Cinta cinematográfica]. Walt Disney Pictures. Estados Unidos.

Del Vecho, P., Lasseter, J. (productores) y Buck, C., Lee, J. (directores). Frozen. (2013). El reino del hielo [Cinta cinematográfica]. Walt Disney Animation Studios. Estados Unidos.

Disney, W (productor) y Hand, D (director). (1937).Blancanieves y los siete enanitos [Cinta cinematográfica]. Walt Disney production. Estados Unidos.

Disney, W (productor) y Geronimi, C ., Jackson, W., Luske, H. (directores). (1950). Cenicienta [Cinta cinematográfica]. Walt Disney production. Estados Unidos.

Disney, W (productor) y Geronimi, C., Clark, L., Larson, E., Reitherman, W. (1959). La bella durmiente [Cinta cinematográfica]. Walt Disney Pictures. Estados Unidos.

Freud, S. (1925). Algunas consecuencias psíquicas de la diferencia anatómica de los sexos. Obras Completas. Tomo XIX. Buenos Aires: Amorrortu.

Hahn, D (productor) y Trousdale G., Wise, K (directores). (1991). La bella y la bestia [Cinta cinematográfica]. Walt Disney Feature Animation. Estados Unidos.

Lacan, J. (1971-1972) ...O peor.El Seminario de Jacques Lacan. Libro 19. Buenos Aires: Paidós.

Lipovetsky, G. (1999).La tercera mujer. Barcelona: Editorial Anagrama.

Mallet, D. (2010). Mordiendo manzanas y besando sapos. México: Grijalbo.

Miller, J-A. (1998). El hueso de un análisis Buenos Aires: Tres Haches.

Miller, J-A. (2012). Entrevista en Registros. Tomo Gris Hombres. Buenos Aires: Ricardi Impresos.

Pentecost, J (productor), y Gabriel, M ., Goldberg, E (directores). (1995). Pocahontas [Cinta cinematográfica]. Walt Disney Pictures. Estados Unidos.

Shurer, O (productor) y Clements R., Musker J (directores). (2016). Moana [Cinta cinematográfica]. Estados Unidos. Walt Disney Pictures. Estados Unidos. 